\title{
Voltando o olhar para o professor: a psicologia e pedagogia caminhando juntas
}

\author{
Silvana C. Tuleski, ${ }^{\star}$ Nádia M. Eidt, ${ }^{\star \star}$ \\ Andria N. Menechinni, ${ }^{\star \star \star}$ Elisângela F. da Silva, ${ }^{\star \star \star \star}$ \\ Dirlene Sponchiado, ${ }^{\star \star \star \star \star}$ Patrícia D. Colchon. ${ }^{\star \star \star \star \star \star}$
}

\section{RESUMO}

O presente estudo busca apresentar o trabalho da Equipe de Estágio do 5o ano de Psicologia da Universidade Estadual de Maringá (UEM), em uma escola pública, no ano de 2000. A importância deste trabalho está na reflexão sobre o papel do psicólogo escolar, bem como de suas práticas, considerando que o trabalho realizado desenvolveu um processo de questionamento das relações estabelecidas nessa escola no que diz respeito à indisciplina e à prática pedagógica. Uma intervenção foi proposta a partir das queixas apresentadas, relacionadas à indisciplina dos alunos das quintas séries. $O$ trabalho envolveu os integrantes da instituição escolar: professores, pais, equipe técnico-pedagógica e alunos. Como resultados pôde-se verificar que alguns integrantes do grupo de professores conseguiram perceber as relações existentes entre indisciplina, contexto escolar e social e prática pedagógica. Além disso, ocorreu uma integração entre os alunos, diminuindo a rivalidade e a indisciplina existentes entre eles.

Palavras-chave: Psicologia escolar. Prática pedagógica. Relação professoraluno. Indisciplina.

* Psicóloga, supervisora de estágio, professora do Departamento de Psicologia da UEM, doutoranda em Educação Escolar - UNESP/Araraquara. Endereço: Rua Francisco Glicério, 517, apto. 22, Zona 7, Maringá - Pr, CEP: 87030-050. E- mail: silvana@ maringa.com.br.

$\star \star \quad P s i c o ́ l o g a$, Mestranda em Psicologia Escolar - PUCCAMP. Bolsista CNPq/Brasil. Endereço: Rua Jacob Berec Stemberg, 208 - Jardim Chapadão, Campinas - SP. CEP: 13066100. E-mail: nadiaeidt@ig.com.br

$\star \star \star$ Psicóloga Clínica, Maringá - Paraná. Endereço: Travessa Liberdade, 175 - Vila Operária, Maringá -PR.E-mail: andriamenechini@ig.com.br

$\star \star \star \star$ Psicóloga da Mongeral Previdência \& Seguros, Goiânia - Goiás Endereço: Rua T 37, n 3659 - Edifício João Paulo II, apto. 807 - Setor Bueno - Goiás, Goiânia. E-mail: lisfontoura@bol.com.br.

$\star \star \star \star \star$ Psicóloga, professora da Univ. Est. de Mato Grosso - UNEMAT Endereço: Rua A, s/n (- Coab São Raimundo - Barra do Bugres - MT - E-mail: dirspon@ hotmail.com

$\star \star \star \star \star \star$ Psicóloga Clínica - Maringá - Paraná. E-mail: patriciacolchon@ yahoo.com.br. 


\title{
Turning our eyes to the teacher: psychology and pedagogy walking together
}

\begin{abstract}
The purpose of this study is to discuss the work of a group of Psychology students from the "State University of Maringá (UEM)" at a public school, in 2000. The importance of their work is the characterization the role of the school psychologist, as well as his practices, which was made possible through a critical examination of the relationships established in that school in regard to indiscipline and teaching practices. The idea of an intervention arose from the complaints expressed and which were related to indiscipline among students in the first year of grammar school. The work involved teachers, parents, the technical-pedagogical team and students. It was observed that some teachers were capable of identifying a relationship between indiscipline, social context, teaching practice and school context. Besides that, it was observed integration among students along with the decline of rivalry and unruly behavior.
\end{abstract}

Keywords: Teaching practices. Indiscipline. Pupil-teacher relationship.

\section{INTRODUÇÃo}

A partir dos dados obtidos em um levantamento de necessidades realizado com os professores e a equipe técnica da escola, foram detectadas queixas como: falta de comprometimento dos pais na educação dos filhos, indisciplina, imaturidade e rivalidade, principalmente entre os alunos da quinta série. Esses fatores seriam os responsáveis pelo alto índice de repetência ocorrido em 1999.

Depois de ouvir a versão dos professores e da equipe técnica, as estagiárias conheceram o ponto de vista dos alunos sobre a questão por meio de uma observação participativa, onde os alunos registraram com desenhos e redações o que pensavam sobre seus professores, coordenadores, diretora e colegas de classe.

A partir da análise desse material foi possível perceber que eles achavam as aulas desinteressantes, com conteúdos ministrados de forma mecânica e sem vinculação com seu cotidiano. Além disso, havia uma cisão entre estudo e prazer. De acordo com Souza (1997), as estratégias que tendem a cindir o estudo e o prazer que este proporciona diminuem o interesse do aluno pelos conteúdos apresentados.

Conforme a mesma autora, em se tratando de indisciplina escolar é importante considerar que este conceito varia de acordo com as exigências de cada um. Em muitos casos, tais exigências são altíssimas e os alunos não têm condições de atendê-las de forma sadia. Além disso, ao termo indisciplina são associados outros, como desvio ou distúrbio, naturalizando a disciplina. Nesse processo, esquece-se 
que tanto para o desenvolvimento do indivíduo quanto da sociedade se fazem necessárias transgressão e agressividade - componentes inerentes ao ser humano.

A equipe de estágio procurou desenvolver um trabalho que atendesse à principal solicitação feita - trabalhar a indisciplina entre alunos de quinta série -, porém, entendendo-se esta queixa como uma produção da escola e da sociedade e não como um processo individual, passível de ser resolvido a partir de uma intervenção clínica - o que responsabilizaria unicamente o indivíduo pela indisciplina escolar.

A Psicologia Institucional, com um modelo conceitual pertencente à Psicologia Social, propõe-se a atuar compreendendo a estrutura, a dinâmica e a Psicologia das instituições, juntamente com uma estratégia de trabalho que oferece instrumentos teóricos para respaldar a entrada do psicólogo na escola como profissional que tem como função ouvir e atuar sobre as queixas apresentadas pela instituição no contexto escolar como um todo.

Diante disso, pensar na concepção do profissional da Psicologia a resposta da educação é o ponto de partida para a tomada de decisões sobre a forma de atuar neste contexto.

\section{DAdos históricos E ATUAIS SOBRE A ATUAÇão do PSiCólogo ESCOLAR}

Historicamente, segundo Yazlle (1997), a Psicologia surge sob uma perspectiva de ciência descontextualizada, desconsiderando os fatores sociais dos fenômenos humanos. Estava preocupada com a ordem e as leis - padrões gerais de comportamentos estabelecidos estatisticamente em comum com a razão instrumental. Dessa forma, caracterizou-se como uma ciência comprometida com a ordem e o controle, em suma, com um projeto social burguês e com as regras sociais decorrentes do capitalismo. O papel da Psicologia, antes mesmo de sua efetivação como profissão, era de caráter normativo e enquadrava os indivíduos nos modelos sociais.

No Brasil, o conhecimento psicológico originou-se de trabalhos cujos fundamentos filosóficos provêm de fontes diversas: psiquiatria, neurologia e medicina social, sobre uma ótica experimentalista e positivista. Conseqüentemente, as práticas pedagógicas se originaram a partir de duas vertentes: o movimento da Escola Nova e a medicina de concepção higienista. Essas duas vertentes constituíram o perfil do psicólogo na instituição escolar, cuja função era ocultar as desigualdades sociais da época. Por essas duas influências a educação brasileira foi-se constituindo por interesses ideológicos mantidos até hoje.

Posteriormente, sob a influência dos movimentos psicológicos internacionais - baseados em explicações fisiológicas, biológicas e físicas para o comportamento humano -, surgiram tentativas de compreender a educação e os processos de aprendizagem sob o enfoque que incluía aspectos de cunho sociológico.

A Psicologia Escolar, enquanto área profissional específica, vinha-se caracterizando pela psicologização das questões educacionais, originando práticas 
individualistas e ajustatórias com ênfase nos processos de aprendizagem e nos procedimentos remediativos.

Esperava-se que o psicólogo fizesse um trabalho clínico na escola, buscando "corrigir" os alunos que não se enquadravam nas regras estabelecidas. Pode-se perceber que a expectativa dos professores e da equipe técnica da escola em questão também era a de que a equipe de estágio explicasse o problema vivenciado na escola pela carência econômica e afetiva das crianças, pela desestrutura familiar, pela falta de limites... nesse discurso, os únicos responsáveis pelo fracasso escolar eram a criança e sua família.

Os psicólogos escolares (KUPFER, 1997), procurando construir um referencial crítico, passaram a reorientar sua prática, adotando o discurso como pressuposto básico. Propuseram a criação de um espaço em que não fosse ouvida apenas a criança, mas seus professores e pais, com o objetivo de pensar a realidade da escola como um processo de construção coletiva. Assim sendo, as soluções não são buscadas a partir de um enfoque individual: é o contexto escolar e suas práticas que constituem o objeto da análise.

Dessa forma, diminuem as cristalizações e os estereótipos, uma vez que o discurso se dinamiza e as pessoas podem se comprometer e responsabilizar-se pelo que fazem e dizem. Esse espaço foi oportunizado em diversas reuniões a fim de se pensar um caminho coletivo para a indisciplina existente nas quintas séries.

Bock (2000), afirma que a naturalização do fenômeno psicológico como gerador de concepções na Psicologia da Educação começa pela escola, que desvalorizou a vida social e não entendeu que deveria se articular com ela e injetar a realidade nas tarefas e reflexões escolares. Verificou-se que este descomprometimento da escola com o social expressou-se nas reflexões feitas pelos professores em um curso organizado pela equipe de estágio sobre sua formação. Eles tinham dificuldade em entender a escola como integrante de um sistema social mais amplo e constantemente influenciada por ele. Em conseqüência disso, os conteúdos eram repassados aos alunos de forma mecânica e não havia compromisso com a análise crítica da realidade em que vivemos.

Em virtude de uma formação deficitária, os psicólogos têm contribuído para a produção do fracasso escolar, na medida em que utilizam como referencial teorias sobre o desenvolvimento da criança descoladas da realidade social na qual esse desenvolvimento toma sentido, ou melhor, na qual, de nossa perspectiva, ele se construiu. "Temos contribuído para que a educação escolar apareça como a grande redentora de nossos problemas sociais, deixando definitivamente ocultados os determinantes econômicos e os interesses políticos desses problemas" (BOCK, 2000, p. 31).

Isso gera cobrança por parte da sociedade e dos integrantes da escola de que a Psicologia ofereça soluções imediatas e remediativas a problemas de ordem pedagógica e estrutural da escola, que é influenciada pelo contexto social. Buscase então, "soluções" no âmbito individual e não no coletivo, negando-se a reflexões críticas em relação à própria escola e sociedade. 


\section{Proposta de intervenÇÃo: REFleXão-AÇÃo-REFleXão}

De acordo com Kupfer (1997), um dos fatores que prejudicam a implantação de propostas educacionais em que o papel da criança/aluno é relevado, encontra-se justamente na necessidade e na dificuldade do professor em assimilar a concepção de criança como ser cognoscente.

A desvalorização da capacidade cognoscente infantil sustentada atualmente é verificada por meio da exclusão do seu discurso e da sua participação no processo educacional.

Como não há a prática de ouvir os alunos, torna-se difícil vê-los como seres totais o que, conseqüentemente, limita as possibilidades de reflexão acerca de novas propostas para o ensino. Essa desvalorização foi percebida na atuação diária dos professores que não acreditavam na capacidade de os alunos correlacionarem os conteúdos aprendidos com a sua realidade social.

A participação da criança nesse processo não deve se configurar como mero exercício físico e motor ou como mera seqüência de tarefas elaboradas pelo professor a serem executadas. A criança participa ativamente quando é capaz de compreender os objetivos de cada tarefa ou exercício executado, e, principalmente, quando seu desenvolvimento particularizado é respeitado. Durante o trabalho realizado com as quintas séries, os alunos demonstraram que a relação e o interesse pelos conteúdos ocorriam de forma significativa quando compreendiam os significados dos mesmos para sua vida cotidiana ou quando eram desafiados a criar, opinar ou refletir sobre os conteúdos, interagindo ativamente com seus colegas, a partir da mediação dos professores. Conseqüentemente, as potencialidades eram valorizadas, a atividade proposta ganhava sentido e a participação aumentava.

Pelo fato de alguns professores não terem essa visão acerca dos alunos, repassavam os conteúdos com uma metodologia presa a resultados, esquecendo por vezes de mostrar sua utilidade prática. Observou-se que os alunos apresentavam um "discurso pronto" acerca da necessidade de estudar para "ser alguém no futuro". Não se percebiam como capazes de construir o conhecimento e de obter prazer através dessa construção.

A prática vivenciada na escola propiciou a percepção de que essa visão da criança continua atualmente na prática dos professores da instituição em questão. Ela é vista como um ser que precisa ser enquadrado nos "moldes" dos adultos. Os professores enfatizavam a importância de a criança ouvir as explicações sobre o conteúdo, quietas em suas cadeiras escolares, sem brincar ou conversar. Dessa forma, fortaleciam a idéia de que crianças das quintas séries são imaturas e indisciplinadas.

Assim, também a indisciplina citada pelos professores tem como um dos motivos a metodologia e os procedimentos de certa forma inadequados. A metodologia por eles utilizada se dá através de tarefas mecânicas, como cópias de exercícios repetitivos e pelos conteúdos ministrados, que possuíam pouca vinculação com o cotidiano dos alunos. 
Na tentativa de buscar estratégias para minimizar a indisciplina, os professores freqüentemente elogiavam uma das turmas como a mais comportada. Esta turma era formada por um grande número de meninas (que, influenciadas por nossa cultura, costumam ser mais quietas que os meninos nessa idade, pois são "mocinhas") e, em geral, seus componentes não eram repetentes. As outras duas salas eram compostas por um número significativo de alunos repetentes e vindos de outras escolas, considerados excessivamente indisciplinados pelos professores. Os alunos repetentes eram altamente estigmatizados, pois já haviam sido "dispensados" de outras escolas.

Esta forma diferenciada de tratar as três turmas de quinta série aumentava a indisciplina e a rivalidade entre elas, pois cada uma acabou assumindo o estereótipo que lhe foi atribuído. Com o objetivo de romper com esse estereótipo, o grupo de estágio propôs o envolvimento dos professores nas discussões a respeito dos motivos da indisciplina entre as quintas séries, assim como o planejamento e a efetivação de uma gincana entre os alunos das três salas. O regulamento incluía a composição de três novas turmas de quintas séries, formadas mediante o sorteio de uma cor. Os professores tiveram dificuldades em se envolver no trabalho proposto, pois repetiram sua forma tradicional de trabalhar os conteúdos e os apresentaram como cópia ou atividades que não exigiam desafio. Os alunos pediam atividades mais interessantes e menos repetitivas, mostrando o desejo de se envolver no processo de construção de seu conhecimento.

Outro objetivo da gincana foi promover um momento de reflexão sobre o processo ensino-aprendizagem, buscando formas mais adequadas para que o processo de transmissão-assimilação dos conteúdos escolares aconteça de forma mais efetiva.

Durante a realização do trabalho na escola, foi percebido que o educador, tal como o aluno, não entende o significado e a razão de ser da disciplina. Em consequiência disso, o professor recorre a todos os meios para manter o aluno quieto em sala de aula, chegando ao ponto de "negociar" abertamente o silêncio por um passeio fora da escola. Tais estratégias acabam por estabelecer uma relação falsa baseada na troca. Além disso, por trás desta proposta é passada a idéia de que estar em sala de aula é algo negativo, pois precisa ser compensado com um prêmio. Para tentar obter esse "prêmio" outras vezes, é provável que o comportamento indisciplinado volte a ocorrer.

A disciplina não deve ser considerada apenas e unicamente como o silêncio e a ordem, nem como um "pré-requisito para a ação pedagógica, [mas sim como] um dos produtos ou efeitos do trabalho cotidiano de sala de aula" (AQUINO, 1998, p. 202).

\section{Além disso,}

A didática reinante ainda considera o professor como o único detentor do saber, em sala de aula. $\mathrm{O}$ aluno deve manter-se horas a fio, calado e atento. O professor vai-se habituando a trabalhar com os "limites do não pode", ao invés de privilegiar 
os "limites da possibilidade", não levando em conta que o objetivo do trabalho pedagógico se efetua do aluno enquanto aluno, isto é, o trabalho pedagógico se efetua para fazer com que a figura do estudante desapareça (CHAUI apud BOARINI, 1998, p. 14).

A teoria de Vygotsky contribui para essa nova visão da criança, atribuindo importância à dimensão social, mediando assim a relação do indivíduo com o mundo. $\mathrm{O}$ aprendizado ocorre mediante a inserção do indivíduo em um grupo cultural, promovendo o desenvolvimento das funções psicológicas superiores (pensamento, percepção, memória, raciocínio e volição).

Segundo esta perspectiva, o processo de desenvolvimento é possibilitado pelo aprendizado e acredita-se que a criança inicia a aprendizagem muito antes de freqüentar a escola. Vygotsky (1998) postula a existência de dois níveis de desenvolvimento infantil - real e potencial. O nível de desenvolvimento real é a capacidade da criança de realizar atividades independentemente. Já o nível de desenvolvimento potencial está relacionado à capacidade que construída, ou seja, a criança consegue realizar determinadas atividades desde que conte com a participação de alguém mais capaz. Com isso, o papel do professor em sala de aula seria o de interferir no meio, fornecendo instruções ou pistas que possibilitem a alteração no desempenho de seu grupo de alunos. A visão dos professores de que as crianças em questão são imaturas está pautada em uma visão organicista e naturalista e passiva de desenvolvimento, em que elas têm um momento certo para aprender. Isso justifica o posicionamento dos professores de procurar normatizar os alunos nos padrões que conhecem.

No cotidiano das escolas, costuma-se avaliar as crianças somente no nível real ou efetivo, do que são capazes de fazer, sem a colaboração de outros. Pensando dessa forma, as crianças que não acompanharem o ritmo da maioria serão consideradas incapazes, tendo que "aprender a aprender", como na visão dos professores da escola em questão. Ao atribuir importância somente aos resultados que a criança apresenta, não se valoriza o nível de desenvolvimento potencial da mesma. De acordo com a teoria histórico-cultural, quando uma criança não consegue realizar sozinha determinada tarefa, mas o faz com a ajuda de outras pessoas mais experientes, está demonstrando que já contém aspectos e partes mais ou menos desenvolvidas de noções e conceitos.

Nessa perspectiva, o papel do professor no processo ensino-aprendizagem "é muito mais atuante do que apenas uma pessoa que oferece condições, que dá pistas para que o aluno construa por si só o conhecimento, como se este aprendesse independentemente da escola" (FACCI, 1998, p.28). Essas visões integram o ideário construtivista e escolanovista. Porém, de acordo com a psicologia histórico-cultural, "[...] a grande tarefa do ensino reside em transmitir à criança aquilo que ela não é capaz de aprender por si só” (DUARTE, 1998 apud FACCI, 1998, p. 28).

Percebeu-se que os professores atuantes na escola em questão reclamam da falta de prestígio atual, pois antigamente eram tratados com reconhecimento, o 
que não condiz mais com sua imagem profissional. Além disso, para justificar o reduzido número de participantes no curso sobre formação docente, alegavam que havia um sentimento de desmotivação diante dessa atividade.

Segundo Facci (1998), sentimentos como estes estão presentes em maior ou menor intensidade no corpo docente da atualidade. O Construtivismo e a Escola Nova, enfatizando a possibilidade de o aluno aprender mediante a mínima interferência do professor, associados à excessiva flexibilização dos currículos escolares propostos por estas abordagens - em nome da "autonomia" do aluno - têm contribuído significativamente para que o professor se descaracterize da sua função profissional, que é ensinar.

No decorrer desse trabalho, percebeu-se que as queixas escolares não mudaram, mas sim a forma com que a Psicologia passou a entendê-las. Em um primeiro momento, os professores e a equipe técnica da escola insistiam em permanecer na posição de clientes para o trabalho psicológico, pois isto significava não questionar a realidade escolar e social em que estavam inseridos. A indisciplina era inicialmente compreendida como algo individual e interior ao aluno, totalmente descontextualizada das relações produzidas no interior da escola.

Ao final do trabalho, alguns integrantes do grupo de professores conseguiram redimensionar o olhar para essas e outras questões, de modo a perceber as relações existentes entre indisciplina, contexto escolar e social e prática pedagógica. Além disso, ocorreu uma certa integração entre os alunos, diminuindo a rivalidade e a indisciplina existente entre eles no início do trabalho.

As propostas de intervenção do grupo de estágio na escola em questão não pretenderam deslocar a "culpa" pelo fracasso escolar de uma categoria para a outra, mas analisar as relações que geravam os problemas e dificuldades no interior desta Instituição. Fica claro que esse trabalho só se efetiva mediante a atuação conjunta do psicólogo e do corpo docente, procurando rever a ação pedagógica cotidiana.

\section{REFERÊNCIAS}

AQUINO, J. G. A indisciplina e a escola atual. Revista da Faculdade de Educação, São Paulo, v. 24, n. 2, p. 181-204, 1998.

BOARINI, M. L. Indisciplina escolar e dificuldades de aprendizagem escolar: questões em debate. Apontamentos, Maringá, n. 69, p. 1-26, 1998.

BOCK, A. B. As influências do Barão de Münchhausen na psicologia da educação. In: TANAMACHI, E. R.; ROCHA, M. L. P. Psicologia e educação: desafios teóricos-práticos. São Paulo: Casa do Psicólogo, 2000. p. 11-34.

FACCI, M. G. D. O psicólogo nas escolas municipais de Maringá: a história de um trabalho e a análise de seus fundamentos teóricos. 1998. Dissertação (Mestrado)Universidade Estadual Paulista, Marília, 1998. 
KUPFER, M. C. M. O que toca à/a psicologia escolar. In: MACHADO, A. M.; SOUZA, Marilene Proença (Org.). Psicologia escolar: em busca de novos rumos. São Paulo: Casa do Psicólogo, 1997.

SOUZA, M. P. A queixa escolar e o predomínio de uma visão de mundo. In: MACHADO, A. M.; SOUZA, M. P. (Org.). Psicologia escolar: em busca de novos rumos. São Paulo: Casa do Psicólogo, 1997.

VYGOTSKY, L. S. A formação social da mente. São Paulo: Martins Fontes, 1998.

YAZLLE, E. G. Atuação do psicólogo escolar: alguns dados históricos. In: CUNHA, B. et al. Psicologia na escola: um pouco de história e algumas histórias. São Paulo: Arte \& Ciências, 1997.

Recebido em: Dezembro/2004 Aceito em: Março/2005 
